\title{
THE 50 YEARS OF RESEARCH AND TEACHING ACTIVITY OF THE DEPARTMENT OF CLIMATOLOGY AT THE WARSAW UNIVERSITY
}

The $50^{\text {th }}$ anniversary of climatology in Warsaw is at the same time an anniversary of Polish climatology. The establishment of the first Chair of Climatology at the Warsaw University in 1951 was at the same time the starting point for the existence of a definite organisational structure, serving the independent development of climatology as the academic discipline.

The establishment of the Chair of Climatology was at that time an important event not just in Poland, but even in Europe as a whole - as seen against the background of the existing European universities.

The emergence of the Chair is due first of all to the activity of Romuald Gumiński. He recognised the need of separation of the study of climates and the teaching of new specialists in this domain. Gumiński undertook an own initiative of establishing a chair of climatology at the university. This initiative was supported by a group of professors in geography from Warsaw. The then Polish authorities expressed consent to this proposal.

Romuald Gumiński made the way for the development of the modern climatology in Poland. This was facilitated by the functions he held, consecutively, of the deputy director and director of the State Meteorological Institute.

Thus, owing to him, Poland got relatively early included in the mainstream of the modern climatological thought. Romuald Gumiński can be considered the founder of the Polish climatology. His ambition was to establish a truly modern research basis, and so also to secure an appropriate education in the field of climatology at the Warsaw University.

Alas, this well promising start of the development of climatology in Warsaw was dramatically interrupted after just a couple of months by the death of Romuald Gumiński on 26 October 1952.

The contribution that Professor Romuald Gumiński made into Polish climatology was appraised very highly by his successors. This is well reflected through the continuation of the research he initiated on the climate of Poland, as well as through the appropriate profile of teaching of students in climatology.

The most important scientific achievements of Romuald Gumiński include: the discrimination of the agricultural-climatic parts of Poland, the evaluation 
of reality of the climatic cycles, and the study of conditioning of the extreme climatic phenomena in Poland. The results of the studies of R. Gumiński with regard to the use of knowledge concerning climate in farming and spatial planning preserved their validity in an astonishing manner.

In February 1953 Wincenty Okołowicz was entrusted with the duty of the head of the Chair of Climatology. Until that time he had been the employee of Nicolas Copernicus University in Torun. He continued as the director of the State Hydrological and Meteorological Institute (1953-1959) and represented Poland in the World Meteorological Organisation (WMO).

Professor Wincenty Okołowicz has also importantly contributed to the teaching and training of young geographers and climatologists. Initially, he conducted courses at the University of Torun, the Higher Pedagogical School in Gdańsk, Higher Agricultural School in Olsztyn, and later on at the University of Warsaw, and periodically in the Military Technical Academy.

For two terms he was the Dean of the Faculty of Biology and the Sciences of the Earth (1960-62 and 1964-66).

During the 23 years that Professor Wincenty Okołowicz was the head of the Department of Climatology at the Institute of Geography of the University of Warsaw as many as 15 doctorates and 125 master theses were defended under his supervision.

He was active in the work of the Geographers' Expert Team with the Main Council of University Education, participating, in particular, in correcting the teaching curricula.

The most important works of Professor Wincenty Okołowicz include: $Z a$ chmurzenie Polski [The cloudiness of Poland] (1964), The Climatic Divisions of the World (1962) and of Poland (1966), both in Polish, Klimatologia ogólna [General climatology; in Polish] (1969) — the handbook distinguished by the Minister's Prize of II ${ }^{\text {nd }}$ degree, the climatic maps for the National Atlas of Poland, concerning air temperature, cloudiness, and snow cover - published in the years 1973-1978. These publications are still being frequently quoted in both Polish and foreign literature, and two of them were translated to English language at the commissions from abroad.

It was upon the initiative of Professor Okołowicz that the publication series was established entitled Prace $i$ Studia Instytutu Geograficznego Uniwersytetu Warszawskiego [Reports and Studies of the Institute of Geography of the University of Warsaw], nowadays appearing as Prace $i$ Studia Geograficzne [Studies in Geography], which opened up for the younger research and teaching staff the possibility of making their work known.

An important event in the domain of climatology, both for Warsaw and for entire Poland, was constituted by the appearance of the doctoral seminar, established by Professor Okołowicz, in 1966, within the Department of Climatology of the University of Warsaw. This seminar taught the skilled personnel for the developing climatology in Poland. This manner of educating Ph.D.'s is being continued currently at the Faculty of Geography and Regional Studies of the University of Warsaw. 
An essential role in the teaching of the students of geography is played by the Climatological Station "University of Warsaw" (with measurements having started in 1956) and the field weather station in Murzynowo by Płock (first measurements in 1969), currently functioning as the "Masovian Geographical Observatory", headed by Dr. W. Lenart and Dr. D. Dobak, both stations having been established upon the initiative of Professor Wincenty Okołowicz.

Professor Okołowicz was very much in favour of educating the climatologists through their participation in research, either referring to the new currents in climatology, coming from the outside, or to own experience from the field studies. He introduced new directions of experimental research, like, in particular, the influence of water bodies and swamps on local climate, and the influence of the town on climate, with special emphasis on atmospheric pollution.

The intense scientific and organisational activity, first of Professor R. Gumiński, and then of Professor W. Okołowicz, were supported by Ad. Professor Zofia Kaczorowska, and by the team of capable young research assistants, including Stanisław Maczak, M.Sc., Marcin Szmidt, M.Sc., and Bronisław Siadek, M.Sc.

In the framework of the first study specialisation, called "hydroclimatology", established in the academic year 1952/53, the teaching was additionally conducted by Dr Stanisław Zych from the State Hydrological and Meteorological Institute (PIHM) - lecture in climatology, and by Dr Janusz Paszyński from the Geoprojekt company - exercises in climatology. The courses in hydrology were conducted by Professor Kazimierz Dębski and Zdzisław Mikulski, M.Sc., from the Main School of Farming Economy in Warsaw.

The necessity of employing the specialists from outside of the University in teaching of a part of the curriculum would also arise in the subsequent years. Thus, for instance, the subject of "methods of climatological elaborations" was several times over commissioned with Ananiasz Rojecki, fulfilling the duties of a self-standing research scholar, the subject of "agricultural climatology" was conducted by Professor Marian Molga, while "synoptic meteorology" - by Stanisław Gadomski and then by Ad. Professor Jerzy Michalczewski.

This enabled the Department of Climatology to attain a high level in both the research carried out and in the teaching of students.

A great contribution to the education of young geographers, and especially of the climatologists, was also made by Zofia Kaczorowska. During 20 years she gave the course lectures on meteorology and climatology for the IInd year of studies. She also lectured on the climate of Poland at the specialisation of physical geography and at the Quaternary specialisation for the students of geology. She was responsible for the master seminars and the preparatory course to them, as well as for the master's workshop. Likewise, she was active in field exercises, as well as in the entry examinations to the Faculty. She would always be very warm and cordial in her attitude towards the students, especially those in need of help. 
Ad. Professor Zofia Kaczorowska, D.Sc., belongs to the group of scholars, who contributed in an essential manner to the development of Polish climatology. Her research activity started in 1933 with the Ph.D. dissertation concerning the causes of the flood discharges of Vistula. She provided an original explanation for the stormy rains, linked with the movement of the low pressure areas from the South.

Special attention should be paid to the D.Sc. dissertation of Zofia Kaczorowska, entitled Precipitation in Poland in a long-term perspective (in Polish), published in 1962. This book is a milestone in Polish climatology. The Author looked for the connection between the periodicity of precipitation and, in particular, the cycles of the sunspots, on the basis of numerous long measurement series, and indicated the existence of the 70-year cycle. She proposed a classification of the annual precipitation totals for Poland, with distinction of the normal, wet, and very wet, as well as dry and very dry years. The probabilities determined for these classes of annual precipitation totals do still preserve their validity as a valuable practical information.

In her capacity of an Ad. Professor in the Department of Climatology of the Institute of Geography, University of Warsaw, Zofia Kaczorowska, D.Sc., tutored herself a dozen or so M.Sc. works. In the years 1968-1975 she supervised four doctoral dissertations.

The handbook she wrote, entitled Weather and climate (in Polish), published by Wydawnictwa Szkolne i Pedagogiczne in the years 1977 and 1985/6, has a definitely high didactic value. This handbook is still being used by teachers, as well as students and graduates of the faculties of geography.

The main research problems, taken up by R. Guminski, continued - and still continue - to be considered within the Department of Climatology of the University of Warsaw. One of the primary research themes, which have been dealt with under the leadership of Professor Wincenty Okołowicz, with a significant assistance from Ad. Professor Zofia Kaczorowska, is the theme of Structure and Regionalisation of the Climate of Poland.

The problem, which is nowadays the main object of study, is constituted by the Natural and Anthropogenic Changes in the Climate of Poland. The work is carried out by the team of the employees of the Department of Climatology, which is headed since 1975 by Professor Maria Stopa-Boryczka.

A significant progress was made in the study of the climate of Poland by the development of the statistical models (multiple regression polynomials), determining the primary features of the fields of air temperature, precipitation, etc., in Poland. The modelling of the fields of meteorological variables made it possible to separate the influences of the latitude, of the distance from the Atlantic Ocean, and the altitude above the sea level in the shaping of the climate of Poland. The impacts of these most important geographical factors are measured with the gradient of the field, expressed through its components: meridional, parallel, and related to altitude. They were determined for the entire area of Poland, for the north-eastern part of the country, for the belts of plains and mountains, as well as for the individual localities. 
Thus, for instance, the zones of dominating influence of the Atlantic Ocean and the Baltic Sea on the climate of Poland, with separation of the impact of the surface forms and relief, have been determined on the basis of the maps of horizontal gradients (in the form of vectors). The deformation of the field of air temperature is measured by the deflection of the horizontal gradients (vectors) from the local meridians (according to the principles of the zonal climate setting).

It should also be emphasised that the best interpolation method is the determination of the empirical functions approximating the field of the meteorological variables.

The main characteristics of the air temperature field in Europe and in other climatic zones have also been determined in this manner.

A significant progress in the study of the changes of the Earth's climate has been made by the identification of the causes of natural coolings and warmings in the $18^{\text {th }}-20^{\text {th }}$ centuries in accordance with the principle that the periodicity of the causes and effects ought to be similar. Hence, it is important to note that the analogous periodicity has been demonstrated of the hypothesised causes, that is - the astronomical variables (solar activity, solar constant, parameters of the solar system), the geological variables (volcanic eruptions), and the effects, that is - the climatological variables (atmospheric zonal circulation - NAO, air temperature, precipitation) and the hydrological ones (river runoff, level of the Baltic Sea).

The similarity of the periodicity of the effects and the hypothetical causes enabled elaboration of the forecasts for the changes in the climate of Europe (including Poland) in the $21^{\text {st }}$ century, according to the interference of climatic cycles.

A novelty is constituted by the new type of forecasts for the $21^{\text {st }}$ century, based upon the changes of value of the North Atlantic Oscillation indicator (NAO), the concentration of the volcanic dust in the atmosphere (DVI), and the solar activity. In this context another novelty is constituted by the demonstration of the dominating role of the volcanic eruptions in the shaping of the climate of Poland during the last two centuries.

The study of the urban climate aims, in particular, at the separation of the influence of anthropogenic factors from the natural changes of climate. The deformation was determined of the fields of meteorological variables, taking place under the influence of urban structures for the entire town and the individual housing estates on the example of Warsaw. Calculation of the correlation between the difference of air temperature in town and in its surroundings and the temperature of the surrounding area allowed for estimation of the rates of warming and cooling of the areas covered with urban structures, as well as of the timing of appearance and disappearance of the urban heat island. In this manner the surplus of cloudiness and precipitation, as well as the shortage of air humidity and the decrease of wind velocity were estimated with respect to the surroundings of Warsaw.

The deformation of the field of air temperature by a town depends not only upon the parameters characterising the town, that is, the area and 
volume of structures and the albedo of the artificial surfaces. It also depends upon the state of the atmosphere, and first of all - upon the directions of advection of the air masses with respect to the distribution of the artificial surfaces and the location of areas covered by urban structures.

In the cognition of the features of urban climate an essential role is played by the determination of the threshold values of air temperature, wind velocity, and cloudiness, beyond which the deformation of the air temperature field is the greatest. An attempt was also undertaken, on the example of Warsaw, of separating the anthropogenic changes in air temperature, having a constant tendency, from its natural periodical fluctuations.

The differences between the air temperature values measured and determined from the models of the temperature field in Poland indicate that the main impact on the urban climate comes from the physical-geographic factors, with the anthropogenic ones playing a secondary role.

The identified regularities of the influence of the geographic and anthropogenic factors on climate and the attempt of separating them are both very important for the modelling and forecasting of the spatial and temporal changes of climate.

A new problem in the study of climate is constituted by the determination of the aerosanitary state of Polish towns, with special emphasis on consideration of the presence of sulphur dioxide in the atmosphere. This involves the determination of the influence exerted by the advection of the air masses on the spatial distribution of the $\mathrm{SO}_{2}$ in Poland, with due account of the cyclonal and anticyclonal settings. Synoptic situations were indicated conducive to the increased concentrations of sulphur dioxide in the air, especially within the areas characterised by a high environmental hazard due to the sulphur compounds. These are the current problems associated with the protection of the atmosphere against too high concentrations of toxic substances.

Further, an interesting result consisted in the indication of the biometeorological conditions bringing high risk for the inhabitants of Warsaw, with consideration of fatal illnesses, as well as the synoptic situations (low pressures, high pressures, atmospheric fronts), conducive to the increased mortality in Warsaw.

Likewise, an important work was carried out on the assessment of the bio-climate of the Polish spas with the cardiovascular profile. This assessment can be made use of by the physicians, directing their patients for a cure depending upon the season of the year. Of special significance is the information on the probability of appearance of the disadvantageous, or even dangerous weather situations, which would require a rapid adaptation of the human organism.

The research results of the Department of Climatology include a number of reports, in which the climate of Poland is analysed from the point of view of the important spheres of practical human activity. Thus, in the study of the urban climate, wind, for instance, is not just an element, which changes its characteristics under the influence of urban structures, but also has 
a cooling function (increasing the cooling of the human organism and the heat losses of the buildings), as well as the one of ventilation of the polluted urban area.

The key problems of climatology are being approached in a direct manner in the framework of the D.Sc. and Ph.D. dissertations, and indirectly through the master's theses.

The D.Sc. dissertation of Zofia Kaczorowska, entitled Precipitation in Poland in a long-term perspective, published in 1962 (in Polish), had a pioneering character. It concerned the dependence of the precipitation upon the number of sunspots, and the tendencies in the precipitation in Poland.

A significant progress in the study of periodicity of climate changes and its causes was made with the D.Sc. dissertation of Jerzy Boryczka, entitled The deterministic-stochastic model of the multi-period climate changes (1984, in Polish). The author introduced into the literature the models simulating the natural (periodical) and the anthropogenic changes of climate, along with the forecasts reaching into the $21^{\text {st }}$ century.

Likewise, the results of the inquiry into synchronicity of the climatic fluctuations in Poland, contained in the Ph.D. dissertation of Elwira Żmudzka, entitled Cyclic air temperature changes in Poland (in Polish), defended in 1999, are also of high significance. Thus, for instance, the eight-year cycle of the air temperature is a characteristic of the temperature field in Poland, similarly as it is the case of the 11-year cycle of seasonal precipitation sums in Poland, whose synchronicity was demonstrated in the Ph.D. dissertation of Anna Michalska (1996).

The domain of interest of Maria Stopa-Boryczka is constituted by the correlation dependencies between the air temperature and the other meteorological elements, as well as geographical factors. The first results of research concerning this subject are provided in her D.Sc. dissertation entitled Thermal features of the climate of Poland (in Polish), published in 1973.

The doctoral dissertation of Krzysztof Olszewski, entitled Transformation of water vapour in lower troposphere over the selected areas of Poland (1973, in Polish), was devoted to the absolute humidity of the air, its daily and annual changes, and the correlation interdependencies with the air masses.

The very first monograph of the climate of Warsaw was written by Urszula Kossowska-Cezak as her Ph.D. dissertation, entitled Singularities of the metropolitan climate on the example of Warsaw (in Polish), defended in 1971.

Then, an important step forward in the study of climate of Warsaw, in the domain of daily changes and meteorological conditions conducive to the appearance of the urban heat island was made with the doctoral dissertation of Jolanta Wawer, entitled Thermal features of the local climate of Warsaw (1993).

Maria Kopacz-Lembowicz devoted her doctoral dissertation on Bio-climate of the spas with cardiovascular profile (1975, in Polish) to the evaluation of climate with respect to human needs, and in particular - to human health.

The doctoral dissertation of Bożena Kicińska, entitled The influence of atmospheric circulation on the concentration of sulphur dioxide in the air in 
Poland (1999, in Polish) concerned the aerosanitary state of the towns of Poland, and the weather conditions, conducive to the high concentrations of the $\mathrm{SO}_{2}$ in the atmosphere, especially on the areas with high environmental hazard arising from sulphur compounds.

Then, Magdalena Kuchcik determined in her doctoral dissertation (2000) the biometeorological conditions, which bring about high health risk for the inhabitants of Warsaw, including the cardiovascular diseases of fatal outcome.

A different direction of study, being developed at the Department, started yet by Professor W. Okolowicz, namely the regional climatology of the world, is well represented by the doctoral dissertation of Danuta Martyn, entitled The climate of the Middle East (1973, in Polish).

The most important link in the process of education of the climatologists is constituted by the master's theses, which usually take the form of the original partial elaborates, contained within a broader context. An example of the thus conceived collaboration of students with the supervising researcher is provided by the series of four reports concerning the extreme temperatures in Poland and the eight reports characterising in an extensive manner the snow cover. The output from these master theses was made use of in the publication of the subject-oriented maps and the climatic division of Poland in the National Atlas of Poland by Professor Wincenty Okołowicz (1973-1976).

The three master's theses devoted to the local climates of the spas, all elaborated in 1959, constitute another example of the collaboration of the students with the supervisor (all four being women in this particular case), with the ultimate effect being constituted by the comparative study by Zofia Kaczorowska of the local climate of the mountain spas of Iwonicz, Żegiestów and Szczawnica (Wiadomości Uzdrowiskowe, issue 1-2, Poznań, 1961, pp. 81-89). These master theses referred to the archival materials from the local weather stations in the elaboration of characteristics of the particular elements of climate, as well as to own microclimatic observations, conducted simultaneously in all the three spas.

There have been relatively many master theses elaborated in collaboration of the entire team of the persons employed at the Department of Climatology, devoted to the climate of the north-eastern Poland. Within this stream of work altogether 85 elaborates were prepared: 63 master theses, 15 journal articles, and seven elaborates executed at the commissions from various institutions. Three of them concerned the Region of the Great Masurian Lakes, six - the Biebrza River Plain, ten - the Middle Vistula River Valley, and seven - the Warsaw Basin. Special attention was paid in these works to the influence exerted by the water bodies and swamps on the meteorological variables. Attention should be paid to these master theses, which constituted the monographs of the individual elements of climate, elaborated in the years $1972-1978$, as well as the monographs of climate of the north-eastern voivodships (provinces) of Poland according to the administrative breakdown introduced in 1975. These monographs were prepared not only on the basis of data from the weather stations of the Institute of Meteorology and Water 
Economy, but also on the basis of the results of own experimental studies, carried out in the framework of the field exercises by the Department of Climatology of the University of Warsaw. The Atlas of climate of north-eastern Poland (in Polish) is the synthesis of the studies conducted to date by the employees and students of the Department (Volume IV - Atlas of interdependencies of the meteorological and geographical parameters in Poland, StopaBoryczka, Martyn, Boryczka, Wawer, Ryczywolska, Kopacz-Lembowicz, Kossowska-Cezak, Lenart, Danielak, Styś, 1986). The most important results of the joint research concern the influence exerted by the surface relief and the water bodies on climate.

It can be considered that a great monograph of the climate of Warsaw is constituted by the 90 master theses devoted to the particular elements of the city's climate, with distinction of the thermal conditions. The results of the studies to date contributed mainly to the cognition of the characteristic and singular features of the climate of Warsaw, as well as of the differentiation of the local climate within town.

The measurements of the differentiation of meteorological elements within town, depending upon the season of the year, part of the daily cycle, and weather situations, made it possible to deal with such issues as:

- the deformation of the fields of meteorological variables on the scale of the entire town, with special emphasis on air temperature (heat island);

- the influence exerted by the character of structures and green areas on the differentiation of climate on a local scale;

- the definition of the role of urban green areas in the shaping of thermal and humidity conditions.

In order to determine the thermal features of the micro-climate of the housing estates the data from the measurement points located in such estates were correlated with the ones from the town's periphery. The relations resulting were described with empirical formulae. An attempt of approaching this problem was undertaken on the example of three housing estates in Warsaw, characterised by the high-rise block buildings, the loose structures (Stawki, Służew nad Dolinka), and the family housing with a high share of greenery (in the area of Olimpijska and Racławicka streets). The results from several master theses devoted to this subject served as the basis for writing the paper entitled Influence of the city on the fields of meteorological variables, published in Urban Ecological Studies in Central and Eastern Europe, Proceedings of the International Symposium, Warszawa-Jabłonna, 24-25 September, Wrocław, 1990 (Stopa-Boryczka, Boryczka, Kopacz-Lembowicz).

The contribution of the master course students has also been significant in the analysis of the partial problems of changes in the climate of Poland and Europe. The biggest number of theses concerned the periodicity and the tendencies of change in air temperature and precipitation in Warsaw and Cracow.

Two master theses were elaborated on the basis of the longest series of temperature measurements outside of Poland (Skrzypczuk, 1993 - Central 
England, Kierzkowska, 1994 - Alps). A part of the relevant calculations was included in the tables and diagrams published in volumes XI and XII of the Atlas of interdependencies of the meteorological and geographical parameters in Poland (Boryczka, Stopa-Boryczka, Błażek, Skrzypczuk, 1998, 1999).

The climate of Poland was the subject of altogether approximately 335 elaborates, including three D.Sc. dissertations, and eleven doctoral dissertations. A part of the results were published in the form of monographs, dissertations (9), atlases (14), and articles (172) in various journals. A part have also been published in Prace i Studia IGUW, Klimatologia, issues 11 (1964-1978) and in volumes 11, 20, 22, and 28 of the Prace $i$ Studia Geograficzne (1992, 1997, 1998, 2001). Some of them were translated into English language, like those appearing in the nine volumes of Miscellanea Geographica (1984-2000), of which four translated and published at the commissions from abroad.

The most important achievements of the Department were presented in 15 issues of Prace $i$ Studia Geograficzne in the climatological series (19642001), in the 14 volumes of the Atlas of interdependencies of the meteorological and geographical parameters in Poland (1974-2000).

Special attention ought to be paid to the five issues of Prace $i$ Studia Geograficzne.

The first of these issues, entitled, Prace i Studia Instytutu Geograficznego Uniwersytetu Warszawskiego - Katedra Klimatologii [Works and Studies of the Geographical Institute of the University of Warsaw - the Chair of Climatology] was put together upon the initiative of Professor Wincenty Okołowicz in 1964. The issue contains the proceedings of a conference meant to mark the $10^{\text {th }}$ anniversary of the Chair of Climatology.

Then, three issues were devoted to the creators of the Warsaw school of climatology:

Issue 10 (1978) was devoted to the $70^{\text {th }}$ anniversary of Professor Wincenty Okołowicz, for many years the head of the Department of Climatology of the University of Warsaw, a person having made an essential contribution to the development of climatology and to the education of an entire generation of climatologists.

Issue 11 (1978) was dedicated to Ad. Professor Zofia Kaczorowska on the occasion of the $75^{\text {th }}$ birthday of this author of the significant publications from the domain of the climate of Poland, a model university teacher and the tutor of the young.

Issue 14 (1998), volume 22 of the Prace $i$ Studia Geograficzne, was published post-mortem at the occasion of the $100^{\text {th }}$ anniversary of Professor Romuald Guminski, the first head of the Chair of Climatology of the University of Warsaw, an outstanding climatologist, highly skilled specialist in the assessment of the climate of Poland for agricultural purposes.

Issue 15 (2001), volume 28 of the Prace i Studia Geograficzne, encompasses the entire 50-years of research and teaching of the graduates of climatology (1951-2000). The volume constitutes a synthesis of the research results with special emphasis on the natural and anthropogenic changes in the climate of Poland. 
The concept of the contents results from the anniversary character of the volume. It provides the information on the history of the Chair of Climatology - with special exposition of the teaching activity and the biographical sketches of the founders of the Warsaw school of climatology, and the lists of their publications. Along with this, the research, teaching, and organisational activity of the current employees of the Department of Climatology of the University of Warsaw in the years 1956-2000 was presented separately. The characteristics of the individual persons include CVs, the more important scientific and didactic achievements, and the lists of publications.

Two final chapters of the volume are also quite informative. They contain the calendar of the more important events from the history of the department of Climatology, as well as the memoirs of the graduates from different years.

The research achievements of the Department of Climatology of the University of Warsaw in the years 1951-2000 were characterised in four chapters: "The directions and the more important results of the study of the natural and anthropogenic changes in the climate of Poland", "The progress in the study of causes of the changes in the Earth's climate in the second half of the 20th century", "The selected results of the study of the climate of Poland, with special consideration of Warsaw", and "The applicability of the elaborates prepared at the Department of Climatology".

The Atlas of interdependencies of the meteorological and geographical parameters in Poland, whose consecutive volumes have been appearing since 27 years, can by now be treated already largely as the departmental publication series. The first volume was published in 1974, the fourteenth — in 2000 . The consecutive volumes of the Atlas differ both in terms of the subject of study and with respect to the original methods of statistical analysis applied therein.

In seven volumes of the Atlas (I-VI and VIII) the fields of climatological elements in Poland were described with empirical formulae. The equations of the straight lines, planes, hyperplanes, and the polynomials of regression of higher degrees with respect to the coordinates of location (latitude and longitude and the altitude above the sea level) define the main features of the fields of temperature, precipitation, etc. Modelling of these fields first of all with the polynomials of higher degrees with respect to the geographical coordinates, which are, simultaneously, the geographical factors determining the climate, turned out to a good instrument for the study of climate. A particular role is being played by the third coordinate of location - the altitude above the sea level. Introduction of this coordinate into the empirical formulae enables attainment of a high precision in the estimation of the values of temperature and precipitation in places, where measurements have never been conducted.

The remaining volumes of the Atlas — volumes VII, IX, XIV, published in the years 1982,1997 , and 2000 - contain the results of the research activity in the domain of changes in the climate of Poland and Europe, and, in particular — the periodicity, the tendencies existing, and the forecasts for the $21^{\text {st }}$ century. 
The studies devoted to identification of the causes of natural cooling and warming of climate in the $18^{\text {th }}-20^{\text {th }}$ centuries brought a significant progress in terms of insight into the climate of the Earth. The demonstration of the analogous periodicity of the hypothetical causes of climate change made it possible to elaborate the forecasts of climate for Europe and for Poland.

The best illustration for the scientific activity in the domain of climate is provided by the list of reports, either by individual scientists, or by research teams, published as scientific work or at the commissions from various institutions (506 scientific reports, 59 popular publications, 47 internal reports, 129 reviews, 6 translations, 13 introductions, and 20 biographical notes, altogether 780 items).

The archives of the Department contain also more than 2200 original maps, elaborated and published by the employees and students of the Department, showing the spatial distribution of various elements of climate, and climatic syntheses, as well as the topo-climatic maps. Some of them might constitute separate bibliographical positions.

Then, the educational and skill improvement effort in the field of climatology is best reflected through the numbers of D.Sc. dissertations (6), Ph.D. dissertations (32), and the master theses (368) from the period between 1952 and 2001.

Our graduates occupy, or occupied, high posts at other universities and various scientific institutions in Poland.

The climatologists from the University of Warsaw have always been, and still are, ready to undertake the research corresponding to the current and future needs in, for instance, protection of the atmosphere, and are well aware of the ecological hazards on both local and global scale. Thus, it appears obvious to us that it is necessary to solve the new problems in the domain of the local, regional, and global forecasts, with due account of the natural, as well as anthropogenic conditioning. At the same time, the traditional research themes, which preserve their validity, should also be followed, with the use of the new, perfected research methodologies.

The golden jubilee of the Department of Climatology of the University of Warsaw provides an exquisite opportunity for a deeper consideration of the development to date of climatology in Poland as a geographic science. Hence, a discussion on the directions of further development of the discipline in the just started $21^{\text {st }}$ century is essential. That is also why the scientific session, having taken place on October 25-27, 2001, in Warsaw, bore the title "The advances in the research on climatic change and its importance for human life and economic activity". 